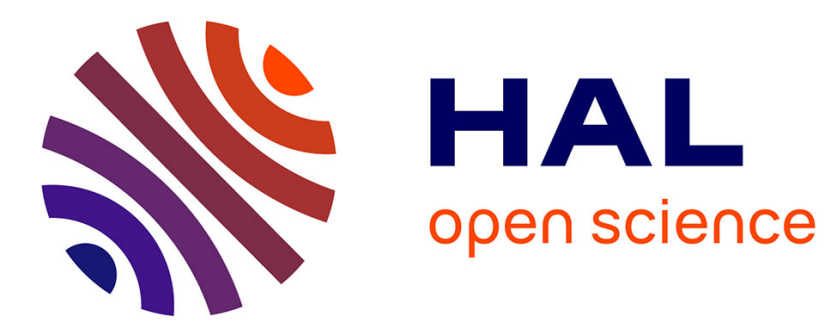

\title{
Plasma agents in bio-decontamination by dc discharges in atmospheric air
}

Zdenko Machala, Lenka Chládeková, Michal Pelach

\section{To cite this version:}

Zdenko Machala, Lenka Chládeková, Michal Pelach. Plasma agents in bio-decontamination by dc discharges in atmospheric air. Journal of Physics D: Applied Physics, 2010, 43 (22), pp.222001. 10.1088/0022-3727/43/22/222001 . hal-00597820

\section{HAL Id: hal-00597820 \\ https://hal.science/hal-00597820}

Submitted on 2 Jun 2011

HAL is a multi-disciplinary open access archive for the deposit and dissemination of scientific research documents, whether they are published or not. The documents may come from teaching and research institutions in France or abroad, or from public or private research centers.
L'archive ouverte pluridisciplinaire HAL, est destinée au dépôt et à la diffusion de documents scientifiques de niveau recherche, publiés ou non, émanant des établissements d'enseignement et de recherche français ou étrangers, des laboratoires publics ou privés. 


\title{
Plasma agents in bio-decontamination by DC discharges in atmospheric air
}

\author{
Zdenko Machala, Lenka Chládeková, Michal Pelach \\ Division of Environmental Physics, Faculty of Mathematics, Physics and Informatics, Comenius \\ University, Mlynská dolina, 84248 Bratislava, Slovakia \\ E-mail: machala@fmph.uniba.sk
}

\begin{abstract}
Bio-decontamination of water and surfaces contaminated by bacteria (Salmonella typhimurium) was investigated in two types of positive DC discharges in atmospheric pressure air, in needle-to-plane geometry: the streamer corona and its transition to a novel regime called transient spark with short high current pulses of limited energy. Both generate cold non-equilibrium plasma. Electro-spraying of the treated water through the needle electrode was applied for the first time and resulted in fast bio-decontamination. Experiments providing separation of various biocidal plasma agents, along with the emission spectra and coupled with oxidation stress measurements in the cell membranes helped better understanding of the mechanisms of microbial inactivation. The indirect exposure of contaminated surfaces to neutral active species was almost as efficient as the direct exposure to the plasma, whereas applying only UV radiation from the plasma had no biocidal effects. Radicals and reactive oxygen species were identified as dominant biocidal agents.
\end{abstract}

PACS. 52.80.Hc Glow; corona - 52.80.Mg Arcs; sparks; lightning; atmospheric electricity- 52.70.Kz Optical (ultraviolet, visible, infrared) measurements - 87.53.Ay Biophysical mechanisms of interaction

Submitted to J. Phys. D: Appl. Phys.

\section{Introduction}

Nonequilibrium plasmas, thanks to their reactive nature, find recently numerous biological and bio-medical applications, especially when operated at atmospheric pressure providing no need of costly vacuum equipment. Atmospheric pressure plasmas applied for sterilization and bio-decontamination are mostly generated by radio-frequency (RF) [1-6] discharges, and various plasma jets and afterglows [1-3, 7-11], usually in rare gases ( $\mathrm{He}$ or $\mathrm{Ar})$ with/without admixtures of $\mathrm{O}_{2}\left(\right.$ or $\left.\mathrm{H}_{2} \mathrm{O}\right)$. The plasma jets are typically blown into the ambient air where the rare gas plasma entrains air components. Air plasmas at atmospheric pressure have additional advantages of no need of special gases and an easy application in ambient environment. Biodecontamination by atmospheric air plasmas was tested in DC [7, 12], dielectric barrier (DBD) [9, 13-20], RF [1], and pulsed discharges [8-10,15]. The plasmas can be also generated directly in water or on water-air boundary [7, 16, 17, 21, 22], which is of great interest for water decontamination. Atmospheric pressure plasmas have been tested on a large variety of prokaryotic microorganisms, such as bacteria, spores, viruses, and some eukaryotic yeasts, fungi and microalgae, resulting in partial disinfection (1-2 log reduction of microbial population) up to complete sterilization. Interaction of the plasmas with the tissues of higher organisms including humans and plasma applications for skin disinfection, wound healing, blood coagulation, dentistry, surgery, inducing apoptosis pathways for cancer treatment, etc. are targeted by a revolutionary novel discipline - plasma medicine [23-27].

In bio-decontamination by nonequilibrium plasma, it is very important to assess the role of various mechanisms involved. Despite there is no general consensus among the authors, the significant mechanisms depend strongly on the plasma composition (gas), temperature, treated microorganisms and the environment, in which they are (air, water, surfaces, etc.). In atmospheric pressure plasmas, the major role is typically attributed to radicals and reactive oxygen species (ROS, e.g. $\mathrm{OH}, \mathrm{O}, \mathrm{O}_{3}$ ) $[1,3,6-10,12,17-19,22]$ and to charged particles, especially $\mathrm{O}_{2}^{-}[14,27]$ affecting the cell membranes. UV radiation plays a role in atmospheric pressure plasmas only if photons in UV C germicide region (220-280 nm) or in vacuum UV are produced $[18,22,28]$. UV C comes typically from $\mathrm{NO} \gamma$ system, which is formed in air at high plasma powers if both $\mathrm{O}$ and $\mathrm{N}$ radicals are generated. It is typical in $\mathrm{RF}$ and microwave discharges and plasma jets 
blown into the air, and high power DBDs. UV C and VUV radiation are also partially produced in discharges in $\operatorname{Ar}[3,4,28]$ or in water [22]. In cold (temperature near ambient) atmospheric air discharges (corona, DBDs, pulsed discharges), NO $\gamma$ and other sources of UV C or VUV radiation are usually not generated, so radicals and reactive oxygen species are identified as the dominant bio-inactivation agents [6$9,11,16,17,29]$.

Our former bio-decontamination investigations with DC discharges in atmospheric air with water were in agreement with this statement and demonstrated the dominant role of radicals and ROS [30]. NO $\gamma$ radiation was only detected in our DC atmospheric pressure glow discharge [31], which was found efficient for biodecontamination but consumed large power [30].

In this paper, the biocidal effects of two plasma sources in atmospheric air with water are investigated positive DC streamer corona (SC) and a novel regime named transient spark (TS). Despite DC applied voltage, these discharges have a pulsed character with nanosecond repetitive pulses. The pulsed plasmas have been demonstrated as an effective source of active species and provide a variety of uses in pollution control, plasma assisted combustion, and bio-decontamination. They are especially convenient for penetration into topographically non-uniform surfaces and cavities, which is applicable e.g. in teeth root canal disinfection $[9,10,15,32]$.

The effects of SC and TS on selected bacteria in water solutions and on surfaces were tested. Biodecontamination of water is important from the viewpoint of waste water cleaning or drinking water disinfection and is involved in all bio-medical applications and food technology, since cells and most foods contain water. Plasma decontamination of various surfaces is important in medicine, e.g. for the sterilization of endoscopes, implants and other heat sensitive materials. The surfaces can be also potentially used as carriers of bio-terrorism agents (e.g. anthrax contaminated letters). The plasmas generated by the studied DC discharges, especially TS, induce chemical effects that are crucial in bio-decontamination and environmental applications, such as VOC abatement that have been successfully tested in the past [33].

We focus on the identification of the dominant plasma agents in bio-inactivation by coupling their electrical characteristics, emission spectra, and biocidal effects in various regimes. Comparing direct with indirect plasma effects enables separation of various biocidal plasma agents (electric field, charged particles, neutral active species, UV radiation). In addition, measurements of the oxidative stress induced in microbial cells applied for the first time in plasma bio-decontamination enable further indicate their respective roles.

\section{Experiments}

\subsection{Experimental set-ups}

The experimental setup for fundamental investigations of the DC discharges in point-to-plane geometry, with a high voltage (HV) hollow needle electrode enabling water flowing through the discharge zone and a plane or mesh electrode is depicted in figure 1. The inter-electrode spacing was varied from $5-10 \mathrm{~mm}$. A positive DC high voltage was applied through the ballast resistor $R$ ( $20 \mathrm{M} \Omega$ for $\mathrm{SC}$ and $\sim 5 \mathrm{M} \Omega$ for TS). The discharge voltage was measured by a high voltage probe Tektronix P6015A. The discharge current was measured: on a $50 \Omega$ (SC) or $1 \Omega$ (TS) resistor and by a Rogowski current monitor PEARSON 2877. The current and voltage signals were processed by a digitizing $200 \mathrm{MHz}$ oscilloscope Tektronix TDS 2024. The discharges were photo- and video-documented with digital cameras Olympus E410 or Nikon Coolpix S10. The emission spectroscopy optical system comprised a dual fibre-optic compact spectrometer Ocean Optics SD2000 with CCD detector for fast scanning in the UV and VIS-NIR regions (200-500 and 500-1050 nm, resolution 0.6-1.2 nm), filters, fused silica lenses, irises, and fibre optics. The discharge setup was placed in the Faraday cage together with the optical components mounted on translation stages, which enabled lateral and vertical scanning capabilities.

The bio-decontamination effects of the DC discharges were tested on flowing water and on direct/indirect treatment of the contaminated solid medium. 


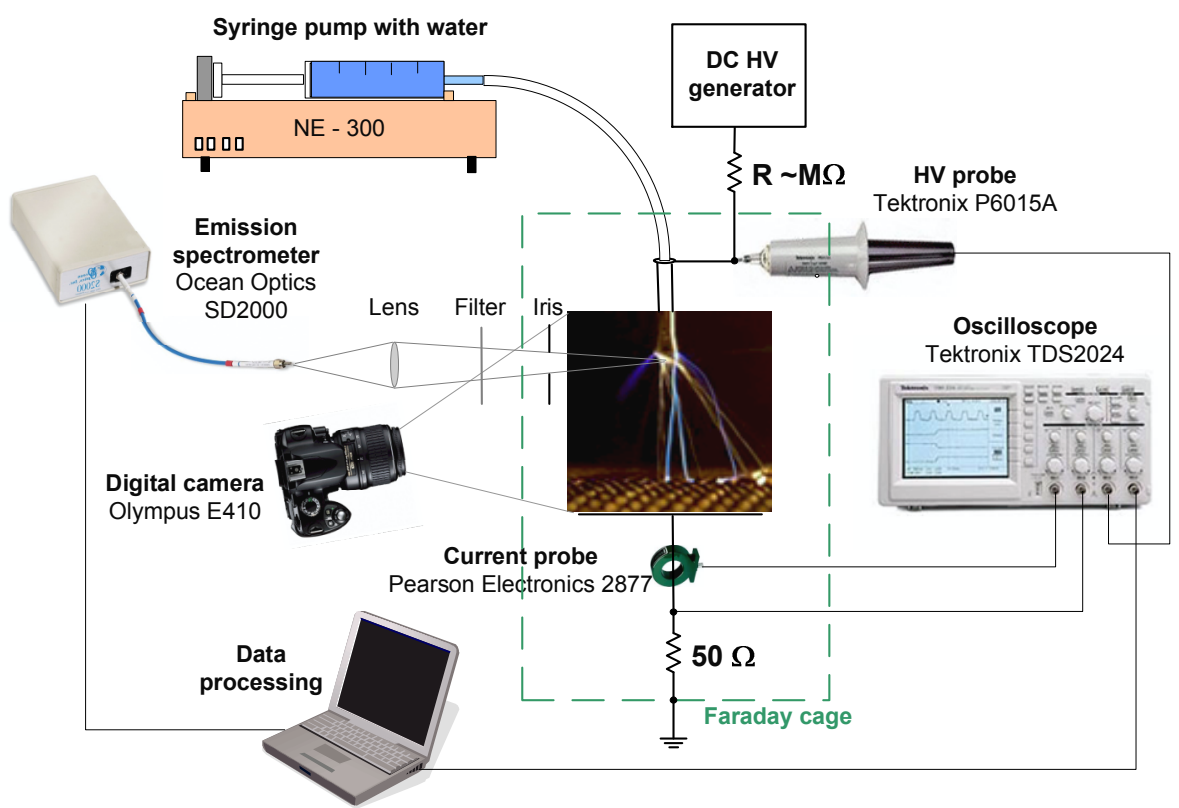

Figure 1. Experimental setup for DC discharges, with a high voltage hollow needle electrode enabling water flowing through the discharge zone and a plane or mesh electrode.

The discharge setup shown in figure 1 enabled the contaminated water to flow directly through the high voltage hollow needle electrode, and so through the corona active region in its proximity. The effect of electrostatic spraying (electro-hydro-dynamic atomization, EHDA) occurred when the high voltage was applied on the needle electrode [34].

We also used point-to-plane electrode geometry for the comparison of direct and indirect plasma effects on contaminated solid agar surfaces. A needle electrode was placed about $1 \mathrm{~cm}$ above the agar surface in the centre of the Petri dish and the discharge was applied for 1 or $2 \mathrm{~min}$. In direct treatment, the agar was grounded with a wire. Indirect plasma effects on the contaminated agar were tested by:

1) placing the grounded mesh electrode $\sim 2 \mathrm{~mm}$ above the agar, this shielded the electric field and trapped the charged particles, letting but neutral particles and partial UV light to reach the agar surface, this concept is similar to [14];

2) placing the $3 \mathrm{~mm}$ thick quartz window onto the agar surface and a grounded ring electrode on its top, this let only the light emitted from the discharge to reach the agar, including UV. We also tested $\mathrm{MgF}_{2}$ window transmitting vacuum $\mathrm{UV}$, this concept is similar to [3].

Figure 2 schematically depicts these arrangements. The agar in the direct treatment (Figure 2a) represents a certain electrical resistance between the discharge and the ground, its typical value was $1-2 \mathrm{k} \Omega$ depending on the water content. In indirect set-ups (Figure 2b,c), a small resistor $r$ was inserted between the mesh (or ring) and the ground to simulate the agar's resistance. Its exact value was set empirically from case to case to make the discharge pulses of about the same amplitude and shape as in the direct treatment on agar. This ensured the same discharge properties in all three set-ups.

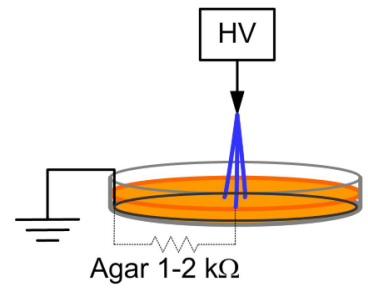

(a)

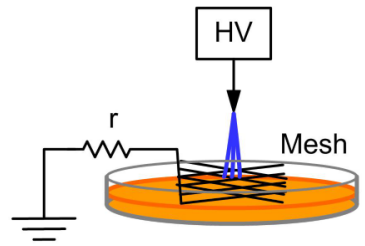

(b)

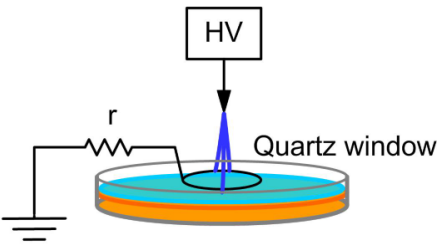

(c)

Figure 2. Schematics of electrode arrangements for (a) direct and (b, c) indirect plasma treatment of contaminated agar plates. (b) Mesh electrode $\sim 2 \mathrm{~mm}$ above agar surface trapped the charged particles and shielded the electric field. (c) Quartz (or $\mathrm{MgF}_{2}$ ) window only transmitted light from the discharge (including UV). 


\subsection{Treated microorganisms, microbial handling and cultivation procedure}

Bio-decontamination effects of investigated DC discharges were tested on selected Gram-negative bacteria Salmonella typhimurium (Salmonella enterica, serovar Typhimurium, strains TA 98 and 100) in water with initial populations from $10^{3}$ to $10^{7}$ colony forming units per $\mathrm{mL}(\mathrm{CFU} / \mathrm{mL})$, or directly spread on the solid nutrient medium (agar, Roth Ltd.) on a Petri dish, about $10^{6}$ per dish. S. typhimurium is a pathogen causing salmonellas diseases; its inactivation is important from the viewpoint of drinking water and food disinfection.

The microbial cultivation was carried out in a sterile environment in the following steps: an overnight bacterial culture was first prepared in a shaker with sterile liquid nutrient. A hot sterile nutrient medium agar - was poured into sterile Petri dishes, on which the bacteria were grown, and solidified. Cultivated bacteria in the liquid nutrient were compared with McFarland turbidity scale to assess their initial population per $\mathrm{mL}$. They were then diluted in water to obtain desired concentrations. The plasma experiments were performed with both discharges, at various parameters and treatment times and repeated 5-8 times. Usually, $50 \mu \mathrm{L}$ of both plasma treated and reference (control) samples were spread on Petri dishes with agar. 3-4 Petri dishes from each sample were taken for statistical evaluation. These were incubated during $12-24 \mathrm{~h}$ in a thermostat at $37^{\circ} \mathrm{C}$. The grown CFUs on the treated and reference samples were counted and evaluated.

\subsection{Measurements of the oxidative stress}

Interaction of ROS with the bacterial cell membranes results in the peroxidation of membrane lipids. The final product of lipoperoxidation is malondialdehyde (MDA), quantifiable by spectrophotometry after the reaction with thiobarbituric acid (TBA) at $90-100 \circ \mathrm{C}$ [35]. This method of thiobarbituric acid reactive substances (TBARS) was applied for the first time to measure the oxidative stress induced in bacteria in distilled water exposed to SC and TS. We assigned the TBARS concentrations from the absorbance of MDA at 532 by using Lambert-Beer's law with the absorption coefficient $1.57 \times 10^{5} \mathrm{~mol}^{-1} \mathrm{~L} \mathrm{~cm}^{-1}$ [35].

\section{Results and discussion}

\subsection{Applied DC discharges}

Two types of DC discharges of both polarities operating in atmospheric air with water were investigated: a well-known streamer corona (SC), and a novel transient spark (TS). These discharges generate nonequilibrium plasmas inducing various chemical and biological effects important in bio-decontamination. Their electrical parameters and emission spectra were documented in detail in our previous works $[31,36]$. The typical voltage and current waveforms of SC and TS discharges in $10 \mathrm{~mm}$ gap with electro-spray of water are shown in figure 3 . When a high voltage of a few $\mathrm{kV}$ is applied to the point electrode, $\mathrm{SC}$ appears, typical with small current pulses of streamers $(\sim 10 \mathrm{~mA})$ with a repetitive frequency of $10-30 \mathrm{kHz}$, during which the discharge voltage remains fairly constant and generates cold plasma $(\sim 300 \mathrm{~K})$.

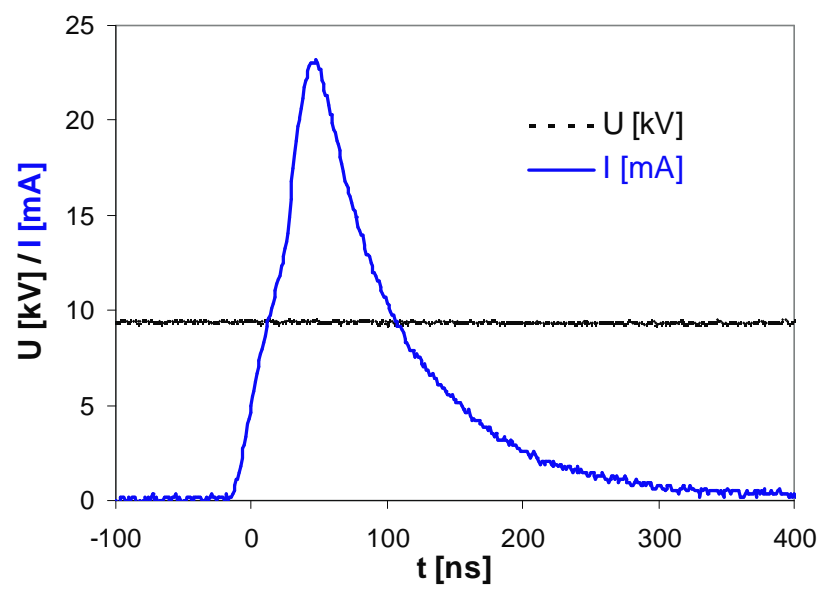

(a)

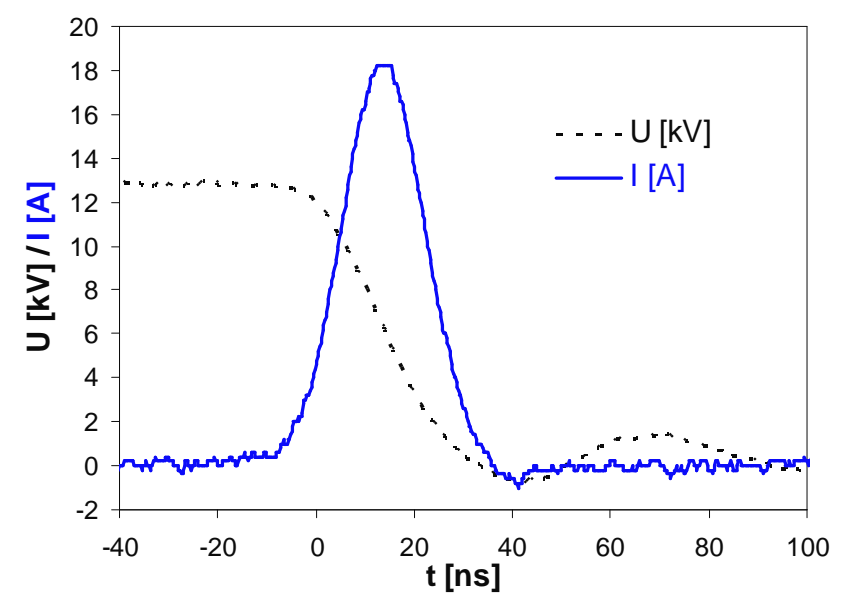

(b)

Figure 3. Typical voltage and current waveforms of (a) SC and (b) TS discharges with electro-spray of water, $10 \mathrm{~mm}$ gap. 
As the voltage is further increased (to $\sim 12 \mathrm{kV}$ in $10 \mathrm{~mm}$ gap), the streamers establish a conductive channel that gradually heats, thus enhancing the reduced electric field $E / N$, which eventually leads to a spark breakdown with excessive current pulse [37].

In our case, the spark pulse current is limited by (1) the ballast resistor $R$ that drops the voltage as the current increases, and (2) the capacity $C$ between the electrodes that is small (order of $10 \mathrm{pF}$ ). $C$ is a sum of the internal capacity of the discharge gap $\left(C_{i n t} \sim 1 \mathrm{pF}\right)$ and the capacities of the high voltage cable $\left(C_{\text {cable }} \approx 5\right.$ $20 \mathrm{pF}$ depending on the length) and the voltage probe $\left(C_{\text {probe }}=3 \mathrm{pF}\right)$. Thus, when the sparks forms, it is only transient since the discharged energy is small (0.1-1 mJ). After the pulse, $C$ is recharged by a growing potential on the stressed electrode and triggers a new pulse. This transient spark becomes then a repetitive streamer-to spark transition discharge, with each spark pulse $(\sim 1 \mathrm{~A})$ preceded by one or a sequence of streamer pulses. The repetitive frequency of pulses is $0.5-10 \mathrm{kHz}$, and increases with the applied voltage. Thanks to the very short pulse duration ( $10-100 \mathrm{~ns})$ given by the small $C$ and a limiting $R$, the plasma cannot reach equilibrium conditions and remains at relatively low gas temperature, depending on frequency, i.e. dissipated power $(\sim 500-1500 \mathrm{~K})$.

\subsection{Optical emission spectroscopy (OES)}

OES in UV-VIS region is a powerful technique of plasma diagnostics, because it gives valuable information on excited atomic and molecular states, enables to determine the rotational and vibrational temperatures and thus the level of nonequilibrium in the plasma, and gives insight in ongoing plasma chemistry $[31,38]$. We employed OES, together with the comparison of the biocidal effects of the DC discharges to better understand the dominant mechanisms involved in bio-decontamination. Both SC and TS generate cold, nonequilibrium plasmas $(300-550 \mathrm{~K})$ in the discharge channel. OES characteristics of the applied discharges described in detail in [31] showed that electrons with the highest energies were present in TS. These electrons initiate dissociations, ionizations and excitations of various species. Atomic $\mathrm{O}, \mathrm{N}$ and $\mathrm{H}$ radicals, and the $\mathrm{N}_{2}{ }^{+}$ions have only been detected in TS, and there were a lot of $\mathrm{OH}$ radicals. Part of $\mathrm{O}$ radicals reacts with air $\mathrm{O}_{2}$ and form ozone $\mathrm{O}_{3}$. There was no UV C radiation detected from SC and TS.

\subsection{Flowing water treatment through the stressed electrode}

The contaminated water flew directly through the high voltage hollow needle electrode, and so through the plasma active zone in its proximity, which substantially improved the volume efficiency compared to our previous set-ups for water treatment [30]. This idea was first introduced for polluted gas treatment through the high voltage needle electrodes [39], we first time applied it for water treatment. The effect of electrostatic spraying (electro-hydro-dynamic atomization, EHDA) occurred when the high voltage was applied on the needle electrode [34]. The electrostatic spraying of contaminated water through the corona active zone contributed to the improved efficiency of bio-decontamination. Figure 4 shows the photographs of the EHDA of water when a high voltage is applied, EHDA with SC, a transition SC-TS perturbing the EHDA and then TS discharge with water sprayed.

The temperature of the treated water did not change in SC and was increased by maximum $10 \mathrm{~K}$ in TS. The lethal heat effect of the discharges to bacteria cannot be considered at all.

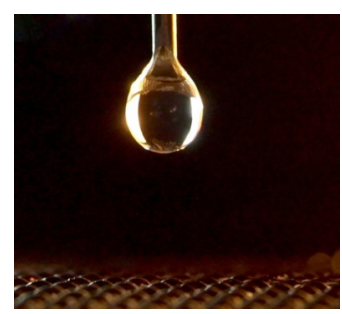

(a)

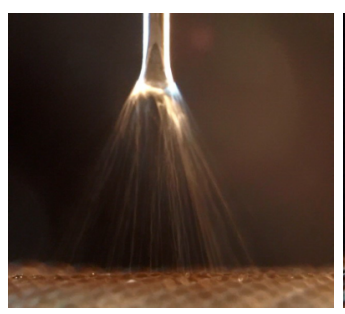

(b)

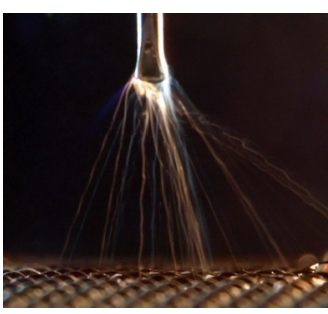

(c)

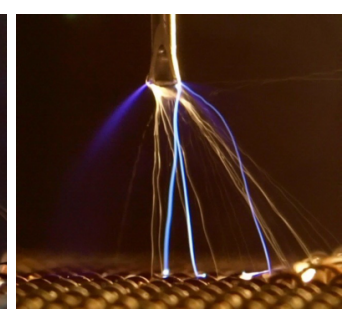

(d)

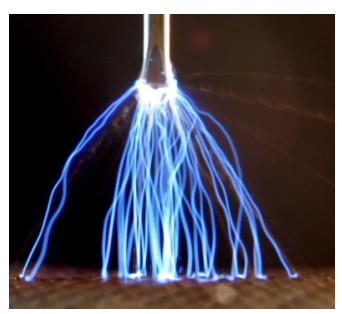

(e)

Figure 4. Photographs of the EHDA of water in $8 \mathrm{~mm}$ gap, water flow rate $0.5 \mathrm{~mL} / \mathrm{min}$ : (a) droplet without a high voltage, (b) EHDA spray with a high voltage applied, $5.5 \mathrm{kV}$, (c) EHDA together with SC, $6.5 \mathrm{kV}$, (d) transition SC-TS, $7.8 \mathrm{kV}$, (e) spray with TS, $9 \mathrm{kV}$. 
The electro-spray water treatment resulted in very short $D$-values (0.1-0.4 $\mathrm{s}$ in both SC and TS), and low energy costs $(0.7-20 \mathrm{~J} / \mathrm{mL}$ per log reduction) in SC. Further improvements of the electro-spray and EHDAdischarge interaction will expectantly enhance the inactivation at lower energy costs.

\subsection{Oxidative stress induced in bacteria}

Figure 5 shows the TBARS concentration gain $\triangle c$ (TBARS) correlated with the bio-decontamination efficiency of SC and TS applied to the electro-sprayed water. The same bacterial samples were irradiated by biocidal UV $\mathrm{C}$ radiation (Hg lamp, $254 \mathrm{~nm}, 1 \mathrm{~min}$ ) for comparison.

UV $\mathrm{C}$ radiation induced almost no $\Delta c$ (TBARS) despite its efficiency was very high. Obviously, UV dominant biocidal mechanism is not peroxidation of cell membranes, albeit radiation induction of ROS in cell nuclei is possible [27]. On the contrary, SC and TS plasma treatments significantly enhanced the TBARS concentration. This indicates that oxidations of cell membranes by ROS are important in microbial inactivation. More ROS is linked with the higher efficiency.

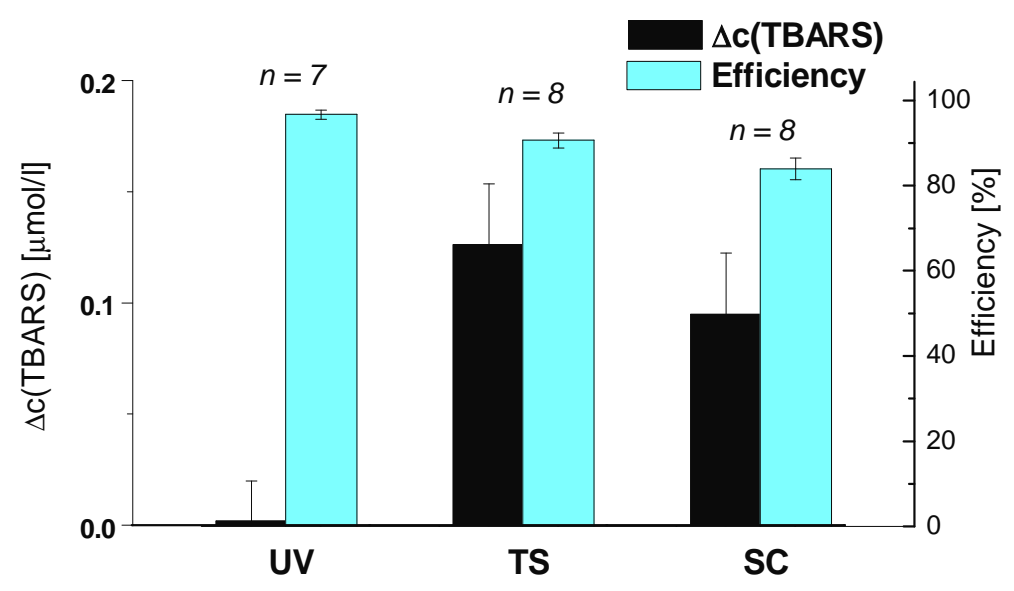

Figure 5. TBARS concentration gains and decontamination efficiencies of $S$. typhimurium in water treated by SC and TS with electro-spray, compared with 1 min exposure to UV C (shown with standard error of the mean, $n$ - number of repeated experiments).

\subsection{Direct vs. indirect plasma treatment}

A comparison of direct and indirect plasma effects on contaminated agar surfaces was aimed at separation of various biocidal plasma agents. We compared direct SC and TS plasma treatment with 2 types of indirect exposure obtained by

1) filtering the charged particles and electric field from neutral radicals and excited species; and

2) applying only UV radiation from the plasma.

The corresponding schematics of the electrode arrangements were shown in figure 2. Figure 6 shows the photographs of the Petri dishes with contaminated agar after direct and both indirect treatments together with the untreated control sample, and a sample treated with $50 \mu \mathrm{L}$ drop of liquid ethanol (96\%) for comparison.

The effects of plasma (and ethanol) on contaminated agar are clearly visible as dark voids, whereas control sample is homogeneously covered by cultivated bacteria (bright). Dark voids with bright spots represent incomplete decontamination (e.g. with ethanol), the spots are CFUs grown from single bacteria. With respect to the total number of bacteria spread on one Petri dish $\left(10^{6}\right)$, a few tens of survived bacteria that cause these bright CFUs in the voids are quite negligible.

Both direct plasma and indirect exposures to neutral reactive species (and partial UV) caused apparent biodecontamination (voids). SC resulted in a larger treated area on the Petri dish, likely due to the electric wind that drives the active species from the point electrode towards and along the agar surface in one preferential direction. TS treatment is more localized in the centre of the dish but more intense. The heat effect of TS on contaminated agar is possible in the very small area under the discharge. TS usually resulted in a tiny hole (1-2 mm diameter) of dried agar. Nevertheless, the area of decontamination (void) was always much larger 
than this tiny hole in its centre. The void kept the ambient temperature after treatment, so we can neglect the heat effect on bacteria. In both indirect treatments, the TS heat was lead out through the mesh (ring) electrode which was not in the direct contact with the agar surface: the heat effect can be excluded.

Interestingly, there was very little difference between the direct and indirect plasma treatments with both discharges, which indicates that neutral reactive species are crucial even in the direct exposure.

Exposure to the UV light only, transmitted by quartz or $\mathrm{MgF}_{2}$ windows demonstrated no visible decontamination; the dishes were almost identical with the control. This correlates with the emission spectra lacking any UV C or VUV radiation in SC and TS.

A similarity of the effects of direct plasma and indirect treatment by reactive neutrals agrees with the emission spectra, oxidation stress measurements and our previous findings [30]. Apparently, radicals and active species $\left(\mathrm{O}, \mathrm{N}, \mathrm{H}, \mathrm{OH}, \mathrm{O}_{3}, \mathrm{O}_{2}{ }^{-}\right)$, especially ROS, represent the dominant biocidal mechanism in atmospheric air SC and TS discharges.
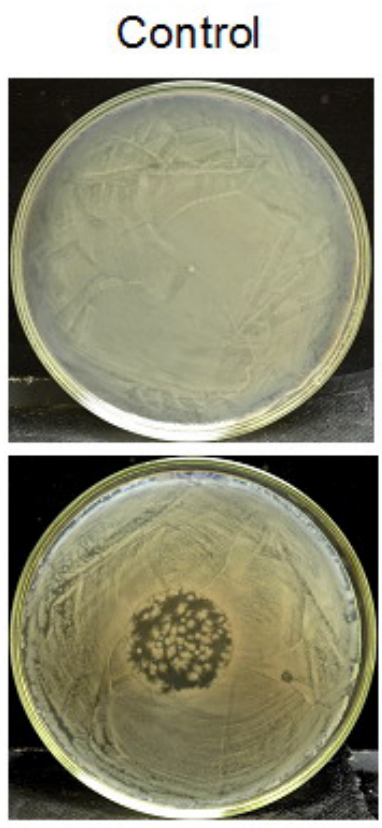

Ethanol
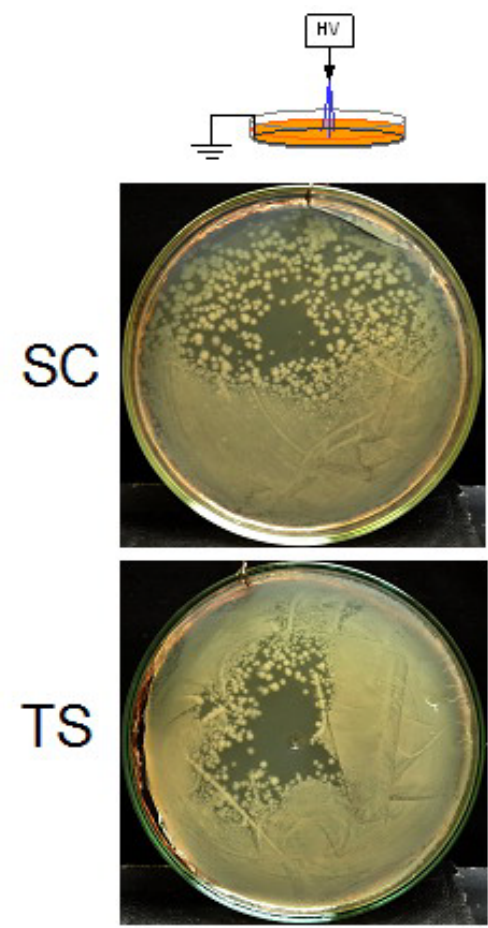

Direct plasma
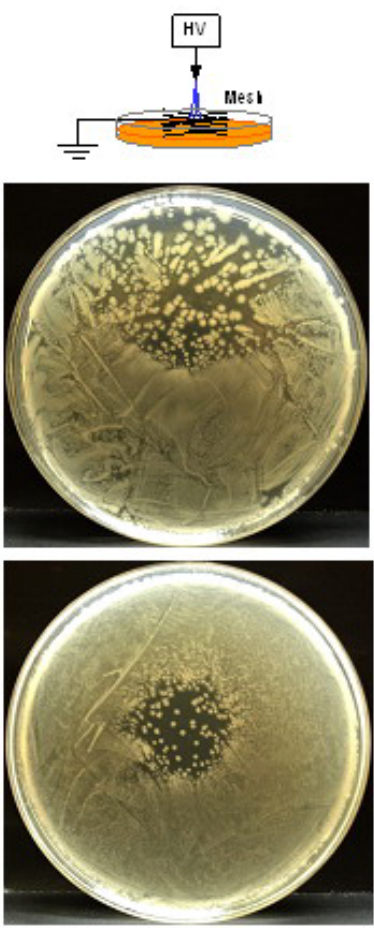

Neutral species
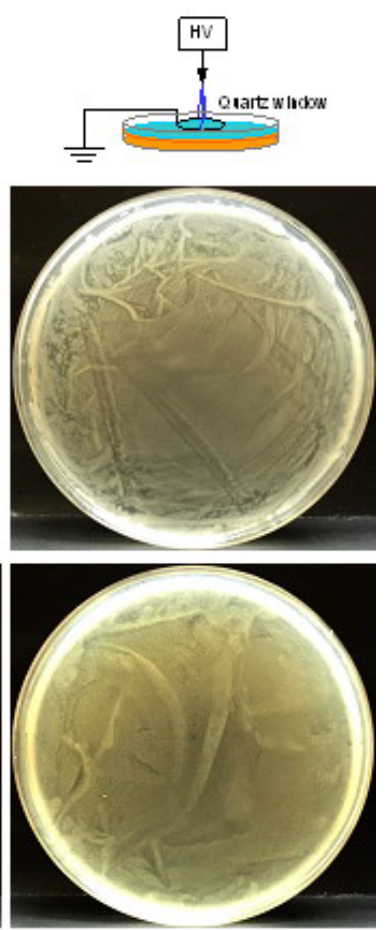

UV only

Figure 6. Photographs of Petri dishes with contaminated agar; left side: untreated control and treated by ethanol, right side: treated by SC (upper row) and TS (lower row) direct, neutral species only, and UV light only.

\section{Conclusions}

Bio-decontamination of water and surfaces contaminated by bacteria (S. typhimurium) was tested in two types of positive DC discharges in atmospheric pressure air in point-to-plane geometry with one electrode submerged in water or in a new arrangement with water sprayed through the plasma zone. The bacteria were handled and their population evaluated by standard microbiology thermostatic growth cultivation procedures.

The streamer corona with small current pulses $(\sim 10 \mathrm{~mA})$ and $10-30 \mathrm{kHz}$ repetitive frequency generates cold (300-350 K) nonequilibrium plasma. With increasing applied voltage, the streamers transit to the novel regime transient spark with short ( $<100 \mathrm{~ns})$ current pulses $(\sim 1-10 \mathrm{~A})$ of $0.5-10 \mathrm{kHz}$ repetitive frequency and very limited energy. Thanks to the very short spark pulse duration given by the small internal capacity of the discharge system and the limiting series resistor, the TS plasma remains relatively cold $(\sim 500 \mathrm{~K})$. The emission spectra of the discharges and the measured temperatures indicate that both SC and TS generate non-equilibrium plasmas with various excited species $\left(\mathrm{N}_{2}{ }^{*}\right)$, and molecular $(\mathrm{OH})$ and atomic $(\mathrm{O}, \mathrm{N}, \mathrm{H})$ radicals. 
Both SC and TS were found very efficient when the treated water was sprayed directly through the high voltage needle electrode and thus through the active discharge zone. Considerable efficiencies at short treatment times resulted in very short $D$-values and relatively low energy costs. EHDA effect occurring with corona discharge in this regime applied for the first time enhanced the efficiency of the process.

The comparisons of direct and two types of indirect exposure of contaminated agar plates to the plasma of $\mathrm{SC}$ and TS enabled the separation of the various biocidal agents. It was demonstrated that the direct exposure and indirect exposure to separated active neutral species generated in the plasma had almost the same effect on bacteria. On the other hand, separated plasma radiation, including UV, had no significant effect. These investigations, together with the emission spectra of the discharges, indicated the major role of radicals and reactive oxygen species $\left(\mathrm{O}, \mathrm{OH}, \mathrm{O}_{3}\right)$. Their role in the plasma treatment was confirmed by the absorption spectroscopic detection of the products of microbial cell membrane oxidation stress in TBARS (thiobarbituric acid reactive substances) method.

In summary, we demonstrated that cold atmospheric air DC discharges can be efficiently used for biodecontamination of water and surfaces. The dominant biocidal plasma agents are radicals and ROS, which agrees with findings published by many other authors.

\section{Acknowledgements}

Effort sponsored by Slovak grant agency VEGA 1/0293/08. We thank I. Jedlovský, B. Pongrác, L. Šikurová, P. Polčic, M. Janda and K. Hensel for their assistance and fruitful discussions.

\section{References}

[1] Montie T C, Kelly-Wintenberg K and Roth J R 2000 IEEE Trans. Plasma Sci. 2841

[2] Sladek R E J and Stoffels E 2005 J. Phys. D: Appl. Phys. 381716

[3] Brandenburg R, Ehlbeck J, Stieber M, Woedtke T v, Zeymer J, Schluter O and Weltmann K-D 2007 Contrib. Plasma Phys. 4772

[4] Sharma A, Pruden A, Stan O and Collins G.J 2006 IEEE Trans. Plasma Sci. 341290

[5] Ohkawa H, Akitsu T, Tsuji M, Kimura H, Kogoma M and Fukushima K 2006 Surf. Coat. Technol. 200 5829

[6] Gweon B, Kim D B, Moon S Y and Choe W 2008 Curr. Appl. Phys. 9625

[7] Akishev Yu, Grushin M, Karalnik V, Trushkin N, Kholodenko V, Chugunov V, Kobzev E, Zhirkova N, Irkhina and Kireev G 2008 Pure Appl. Chem. 801953

[8] Pointu A-M, Ricard A, Dodet B, Odic E, Larbre J and Ganciu M 2005 J. Phys. D: Appl. Phys. 381905

[9] Deng X, Shi J, and Kong M G 2006 IEEE Trans. Plasma Sci. 341310

[10] Jiang C, Chen M-T, Gorur A, Schaudinn C, Jaramillo D E, Costerton J W, Sedghizadeh P P, Vernier P T and Gundersen M A 2009 Plasma Process. Polym. 6 Doi: 10.1002/ppap. 200800133

[11] Lu X, Ye T, Cao Y, Sun Z, Xiong Q, Tang Z, Xiong Z, Hu J, Jiang Z and Pan Y 2008 J. Appl. Phys. 104053309

[12] Sigmond R S, Kurdelova B and Kurdel M 1999 Czech. J. Phys. 49405

[13] Efremov N M, Adamiak B Y, Blochin V I, Dadashev S J, Dmitriev K I, Gryaznova O P and Jusbashev V F 2000 IEEE Trans. Plasma Sci. 28238

[14] Fridman G, Brooks A D, Balasubramanian M, Fridman A, Gutsol A, Vasilets V N, Ayan H and Friedman H G 2007 Plasma Process. Polym. 4370

[15] Ayan H, Staack D, Fridman G, Gutsol A, Muhkin Y, Starikovskii A, Fridman A and Friedman G 2009 J. Phys. D: Appl. Phys. 42125202

[16] Tang Y Z, Lu X P, Laroussi M and Dobbs F C 2008 Plasma Process. Polym. 5552

[17] Qiong T, Wenju J, Zhang Y, Zhishan Y and Mariana L T 2009 J. Phys. D: Appl. Phys. 42095203

[18] Laroussi M and Leipold F 2004 Int. J. Mass Spectrom. 23381 
[19] Tanino M, Xilu W, Takashima K, Katsura S and Mizuno A 2007 Int J. Plasma Environ. Sci. Technol. 1 102

[20] Yasuda H, Hashimoto M, Rahman M, Takashima K and Mizuno A 2008 Plasma Process. Polym. 5615

[21] Mizuno A and Hori Y 1988 IEEE Trans. Industry Appl. 24387

[22] Lukeš P, Člupek M, Babický V and Šunka P 2008 Plasma Sources Sci. Technol. 17024012

[23] Fridman G, Friedman G, Gutsol A, Shekhter A B, Vasilets V N and Fridman A 2008 Plasma Process. Polym. 5503

[24] Kramer A, Lindequist U, Weltmann K-D, Wilke C and von Woedtke T 2008 GMS Krankenhaushyg. Interdiszip. 3, 1

[25] Stoffels E, Kieft I E, Sladek R E J, Van Den Bedem L J M, Van Der Laan E P and Steinbuch M 2006 Plasma Sources Sci. Technol. 15 S169

[26] Kong M G, Koesen G, Morfill G, Nosenko T, Shimizu T, van Dijk J and Zimmermann J L 2009 New J. Phys. 11115012

[27] Dobrynin D, Fridman G, Friedman G and Fridman A 2009 New J. Phys. 11115020

[28] Heise M, Neff W, Franken O, Muranyi P and Wunderlich J 2004 Plasmas and Polymers 923

[29] Laroussi M 2005 Plasma Process. Polym. 2391

[30] Machala Z, Jedlovský I, Chládeková L, Pongrác B, Giertl D, Janda M, Šikurová L and Polčic P 2009 Eur. J. Phys. D 47195

[31] Machala Z, Janda M, Hensel K, Jedlovský I, Leštinská L, Foltin V, Martišovitš V and Morvová M 2007 J. Mol. Spectrosc. 243194

[32] Lu X, Cao Y, Yang P, Sun Z, Xiong Q, Xiong Z, Xian Y and Pan Y 2009 IEEE Trans. Plasma Sci. 37

[33] Machala Z, Morvová M, Marode E and Morva 2000 J. Phys. D: Appl. Phys. 333198

[34] Borra J-P, Ehouarn P and Boulaud D 2004 J. Aerosol Sci. 351313

[35] Bachowski G J, Pintar T J and Girotti A W 1991 Photochem. Photobiol. 53481

[36] Machala Z, Jedlovský I and Martišovitš V 2008 IEEE Trans. Plasma Sci. 36918

[37] Marode E, Bastien F and Bakker M 1979 J. Appl. Phys. 50140

[38] Laux C O, Spence T G, Kruger C H and Zare R N 2003 Plasma Sources Sci. Technol. 12125

[39] Pekárek S, Kř́íha V, Pospíśil M and Viden I 2001 J. Phys. D: Appl. Phys. 341 